\title{
Physical and psychosocial side-effects of brachytherapy: a questionnaire survey
}

\author{
Sara Ferenc, MScl, Piotr Rzymski, PhD, Asst. Prof.! Prof. Janusz Skowronek, MD, PhD²,3, Jacek Karczewski, PhD, Asst. Prof! \\ IFaculty of Health Sciences, Poznan University of Medical Sciences, Poznan, ${ }^{2}$ Department of Electroradiology, Faculty of Health Sciences, \\ Poznan University of Medical Sciences, Poznan, ${ }^{3}$ Greater Poland Cancer Centre, Poznan, Poland
}

\begin{abstract}
Purpose: Brachytherapy (BT) plays an important role in cancer treatment. Like any other medical therapy it may, however, induce side effects whose recognition can affect the patient's quality of life. Therefore, the present study evaluated the frequency and severity of physical and psychosocial adverse effects of BT.

Material and methods: Patients $(n=70)$ undergoing high-dose-rate (HDR) BT or low-dose-rate (LDR) of head and neck, breast, and prostate cancers were interviewed face-to-face at the end of their course of treatment. Interviews concerned the occurrence of 35 physical (dermatological, gastroenterological, neurological, ocular, pulmonological, and urological) and 10 psychosocial side effects of BT.

Results: A high percentage of patients reported that BT decreased their life satisfaction (54.3\%), sense of security $(41.4 \%)$, and self-esteem (34.3\%). The highest frequency of gastroenterological and urological symptoms was reported by prostate cancer patients. Cigarette smoking increased the frequency of nausea, dyschezia, and weight loss. Overweight patients were characterized by an increased rate of urinary incontinence and dyschezia, as well as more pronounced decrease of self-esteem and sense of security following BT treatment.

Conclusions: These findings are not only highly relevant to the way patients can be prepared for the therapy but also have a bearing on ways to minimize the number and severity of BT side effects.

Key words: brachytherapy, breast cancer, head and neck cancer, prostate cancer, side effects, quality of life.

\section{Purpose}

Brachytherapy (BT), a type of radiotherapy using energy from radionuclides inserted directly into the tumor, is increasingly used in cancer treatment. It has become a standard therapy for cervical cancer and an important part of the treatment guidelines for other malignancies including head and neck, skin, breast, and prostate [1, 2]. Compared to external beam radiotherapy (EBRT), it has the potential to deliver an ablative radiation dose over a short time period directly to the altered tissue area with the advantage of a rapid fall-off in dose and consequent sparing of neighboring organs. As a result, the patient is allowed to complete the treatment sooner and the risks of a second cancer are lower than in conventional radiotherapy [3].

Generally, two competitive techniques of BT are commonly and increasingly used: low-dose-rate (LDR), involving permanent implantation of radioactive seeds (in prostate cancer), and high-dose-rate (HDR) with the dose delivered from a single high-activity radioactive source (usually iridium $192\left[{ }^{192} \mathrm{Ir}\right]$ or cobalt $60\left[{ }^{60} \mathrm{Co}\right]$ ). Each method has its advantages and disadvantages. In many coun- tries, including Poland, both LDR and HDR are being used what allows comparison of their efficiency and side effects $[4,5]$. Moreover, a combination of BT and EBRT has been shown to be an effective treatment for some types of malignancies, e.g. cervical cancer [6]. Consecutively, in advanced cancers BT can be combined with chemotherapy (chemoradiotherapy) to improve survival and decrease the risk of disease recurrence [7].

As in the case of any other medical treatment, BT in the form of LDR or HDR, applied alone or in combination with EBRT or pharmacological methods can generate various side effects, which may profoundly decrease patients quality of life $[8,9]$. The overall toxicity of BT is a resultant of the treatment type, irradiated body area, the individual characteristics, and susceptibility of patients. The acute toxicity of radiation therapy is usually evaluated using morbidity scoring criteria, which is useful in the comparison of side effects induced by various types of radiotherapy methods and patient conditions $[10,11,12]$. To the best of our knowledge, no study has so far evaluated the side effects of BT as perceived by patients, or assessed the occurrence and severity of these side effects in relation to different patient characteristics. 
The aim of the following study was to determine the frequency and severity of various physical and psychosocial side-effects of HDR BT and LDR BT in patients shortly after completing the treatment plan. The research also aimed to identify, which patient characteristics (including age, weight, cigarette smoking, and alcohol consumption) may influence the occurrence of early toxic effects of BT. The identification of factors, which can increase the frequency of BT side effects, is potentially useful in the preparation of patients for therapy. It may help reduce the severity of adverse events and also have a beneficial impact on the patient's quality of life following the treatment.

\section{Material and methods}

\section{Studied group}

A group of 70 consecutive patients who underwent LDR (prostate cancer) or HDR (breast cancer, head and

Table 1. Demographical characteristics of patients undergoing brachytherapy enrolled in the study

\begin{tabular}{|c|c|}
\hline Characteristic & $N=70$ \\
\hline \multicolumn{2}{|l|}{ Gender $n(\%)$} \\
\hline Female & $14(20)$ \\
\hline Male & $56(80)$ \\
\hline \multicolumn{2}{|l|}{ Age } \\
\hline Mean (years \pm SD) & $66.9 \pm 10.3$ \\
\hline Median (range) years & $67.0(47.0-95.0)$ \\
\hline \multicolumn{2}{|l|}{ Body mass index } \\
\hline Mean \pm SD & $28.3 \pm 4.3$ \\
\hline Median (range) & $28.0(18.8-41.4)$ \\
\hline Normal weight (BMI 18.5-24.9), $n$ (\%) & $55(78.6)$ \\
\hline Overweight (BMI > 25.0), $n$ (\%) & $15(21.4)$ \\
\hline \multicolumn{2}{|l|}{ Number of brachytherapy treatments } \\
\hline Median (range) months & $2.0(1.0-6.0)$ \\
\hline \multicolumn{2}{|l|}{ Radiated body part, $n$ (\%) } \\
\hline Prostate cancer & $49(70.0)$ \\
\hline Breast cancer & 15 (21.4), incl. one male \\
\hline Head and neck cancer & $6(8.6)$ \\
\hline \multicolumn{2}{|c|}{ Smoking behaviour during therapy period, $n(\%)$} \\
\hline Non-smoking & $60(85.7)$ \\
\hline Smoking & $10(14.3)$ \\
\hline \multicolumn{2}{|c|}{ Drinking behaviour during therapy period, $n(\%)$} \\
\hline Non-drinking & $43(61.4)$ \\
\hline Drinking & 27 (38.6) \\
\hline
\end{tabular}

neck cancer, prostate cancer) BT at the Greater Poland Cancer Centre (Poznan, Poland) were enrolled into the study. All individuals were Caucasian and underwent BT monotherapy. Patients undergoing it in combination with EBRT, chemotherapy, or hormone therapy were excluded from the study. The treatment was performed using the MicroSelectron HDR and Oncentra Masterplan vs $3.2^{\circledR}$ (Nucletron ${ }^{\circledR}$, an Elekta company, Elekta $\mathrm{AB}$, Stockholm, Sweden) treatment planning system. For LDR BT in prostate cancer, the SPOT/SWIFT Oncentra Masterplan vs. 3.2 ${ }^{\circledR}$ (Nucletron $^{\circledR}$ ) was also used. For prostate cancer, HDR BT in 3 fractions of $10.5 \mathrm{~Gy}$, or in LDR BT 145 Gy (total dose) were given. For breast cancer (accelerated partial breast iradiation - APBI), 10 fractions of $3.4 \mathrm{~Gy}$ were given. For head and neck cancer, 10 fractions of 5 Gy were applied. All patients were interviewed face-to-face at the end of their course of treatment. Interviews concerned the occurrence of 35 physical and 10 psychosocial side effects of BT. The former were categorized into 6 groups including dermatological (3), gastroenterological (16), neurological (8), ocular (2), pulmonological (3), and urological (3) symptoms. Patients, divided into three groups according to the treated cancer type, were asked to describe the severity of each physical symptom using a five point scale ("not occurring", "mild", "moderate", "intense", "very intense"). The effect of BT on psychosocial function was described using a four point scale ("no effect", "mild effect", "moderate effect", "strong effect"). Information on gender, age, body mass index (BMI), smoking, and drinking habits, as well as radiated body part and number of BT treatments was acquired for each enrolled patient.

The study was approved by board of directors of Greater Poland Cancer Centre and its design was consistent with the Declaration of Helsinki.

\section{Statistical analyses}

Statistical analyses were performed using the Statistica v.10.0 software package (StatSoft, Tulsa, OK, USA). Pearson's $\chi^{2}$ test was applied to compare the frequencies of the answers among the different groups. The relationship between the two datasets was determined with non-parametric Spearman's rank correlation coefficient. $P$ value $<0.05$ was considered as statistically significant.

\section{Results}

\section{Demographical characteristics}

The demographical characteristics of the BT patients enrolled in the study are presented in Table 1. All patients were interviewed after completing their planned HDR and LDR BT therapy of head and neck, breast, or prostate cancer. The group included 56 males $(80 \%)$ and 14 females $(20 \%)$ of a mean age of $66.9 \pm 10.3$. The majority of patients were non-smoking $(85.7 \%)$ and did not drink alcohol $(61.4 \%)$ during the therapy. Due to low number of patients treated at head and neck area, the statistical comparison were conducted only between groups treated for breast or prostate cancer. 
Table 2. The frequency (\%) of gastroenterological side effects of brachytherapy according to the radiated body part and patient characteristics. Asterisks indicate statistical difference between compared groups $(p<0.05$, $\chi^{2}$ test). Head and neck group was excluded from comparison due to low number of employed patients

\begin{tabular}{|c|c|c|c|c|c|c|c|c|c|c|c|c|c|}
\hline & \multicolumn{4}{|c|}{ Radiated body region } & \multicolumn{3}{|c|}{$\mathrm{BMI}$} & \multicolumn{3}{|c|}{ Cigarettes } & \multicolumn{3}{|c|}{ Alcohol } \\
\hline & $\begin{array}{c}\text { Head } \\
\text { and neck }\end{array}$ & Breast & Prostate & $p$ & Normal & Overweight & $p$ & $\begin{array}{c}\text { Non- } \\
\text { smoking }\end{array}$ & Smoking & $p$ & $\begin{array}{c}\text { Non- } \\
\text { drinking }\end{array}$ & Drinking & $p$ \\
\hline Dry mouth & 33.3 & 26.7 & 24.5 & & 20.0 & 27.7 & & 26.7 & 20.0 & & 25.6 & 25.6 & \\
\hline $\begin{array}{l}\text { Throat muco- } \\
\text { sitis }\end{array}$ & 16.7 & 13.3 & 12.2 & & 13.3 & 12.7 & & 13.3 & 10.0 & & 16.3 & 7.4 & \\
\hline Mouth odour & 16.7 & 13.3 & 14.3 & & 13.3 & 14.5 & & 13.3 & 20.0 & & 18.6 & 7.4 & \\
\hline $\begin{array}{l}\text { Chewing } \\
\text { difficulty }\end{array}$ & 16.7 & 0.0 & 4.1 & * & 0.0 & 5.4 & & 3.3 & 10.0 & & 0.0 & 7.0 & * \\
\hline Dysphagia & 33.3 & 0.0 & 4.1 & * & 6.7 & 5.4 & & 5.0 & 10.0 & & 6.7 & 3.7 & \\
\hline Impaired taste & 16.7 & 0.0 & 6.1 & & 0.0 & 7.7 & & 5.0 & 10.0 & & 9.3 & 0.0 & * \\
\hline Appetite loss & 0.0 & 6.7 & 20.4 & & 26.7 & 12.7 & & 15.0 & 20.0 & & 16.3 & 14.8 & \\
\hline Satiety & 0.0 & 13.3 & 26.5 & & 13.3 & 23.6 & & 21.7 & 20.0 & & 20.9 & 22.2 & \\
\hline Nausea & 16.7 & 6.7 & 28.6 & & 20.0 & 23.6 & & 20.0 & 40.0 & * & 20.9 & 25.9 & \\
\hline Vomiting & 0.0 & 0.0 & 0.0 & & 26.7 & 20.0 & & 0.0 & 0.0 & & 0.0 & 0.0 & \\
\hline Diarrhoea & 0.0 & 20.0 & 18.4 & & 20.0 & 16.4 & & 16.7 & 20.0 & & 20.9 & 11.1 & \\
\hline Rectal pain & 0.0 & 6.7 & 10.2 & & 13.3 & 7.3 & & 0.0 & 20.0 & * & 11.6 & 3.7 & \\
\hline Dyschezia & 0.0 & 13.3 & 28.6 & & 16.4 & 46.7 & * & 20.0 & 40.0 & * & 20.9 & 25.9 & \\
\hline Bloating & 0.0 & 26.7 & 40.9 & * & 33.3 & 34.5 & & 33.3 & 40.0 & & 32.6 & 37.0 & \\
\hline Weight gain & 0.0 & 6.7 & 36.7 & * & 20.0 & 29.1 & & 28.3 & 20.0 & & 27.9 & 25.9 & \\
\hline Weight loss & 0.0 & 13.3 & 12.2 & & 13.3 & 10.9 & & 6.7 & 40.0 & * & 11.6 & 11.1 & \\
\hline
\end{tabular}

\section{Frequency of side effects}

The irradiated body part affected the frequency of the studied symptoms (Table 2, Table 3). Chewing difficulties and dysphagia were reported most often by patients treated in the head and neck area. They did not, however, report headaches, concentration difficulties, or insomnia. In turn, BT of prostate cancer was characterized by the greatest frequency of bloating and weight gain, and a relatively high frequency of neurological symptoms. Patients irradiated with breast cancer were found to report skin inflammation more often than prostate cancer patients (Table 3 ).

In general, patient characteristics affected the frequencies of side effects (Table 2). Overweight subjects reported dyschezia more frequently. Cigarette smoking significantly increased the frequency of nausea, rectal pain, dyschezia, and weight loss following the BT treatment. Patients who consumed alcohol during the period of BT treatment reported chewing difficulties more often but none of them experienced taste impairment (Table 2).

Urinary incontinence was reported more frequently by alcohol-drinking patients but was significantly lower in the overweight group. Overweight subjects experienced a higher frequency of insomnia while non-smoking and alcohol-drinking patients suffered more commonly from drowsiness. No differences in the frequencies of ocular or pulmonological side effects were observed in patients differing in weight, cigarette smoking, and alcohol consumption (Table 3).

Brachytherapy treatment was found to be responsible for various adverse psychosocial effects in the studied group (Fig. 1). Over $50 \%$ of patients reported that the treatment had decreased their general life satisfaction, over $40 \%$ that it decreased their sense of security, while over $30 \%$ stated that it had affected their self-esteem and altered their financial status. No differences in the frequency of any psychosocial effects of BT were reported in groups of patients suffering from different forms of cancer. These effects appeared not to depend on smoking or drinking habits. However, it was found that compared to patients with BMI in the 18.5-24.9 range, overweight patients experienced a higher frequency of decreased selfesteem $(9.1$ vs. $40.0 \% ; p<0.05)$ and a lessened sense of security ( 38.2 vs. $53.3 \% ; p<0.05)$ following the BT treatment.

\section{Intensity of side effects}

In general, the frequency of side effects reported as "intense" or "very intense" was relatively low. For dermatological symptoms, the greatest severity was reported for skin inflammation (4.3\% reported as "very intense" 
Table 3. The frequency (\%) of dermatological (D), neurological (N), ocular (O), pulmonological (P), and urological (U) side effects of brachytherapy according to the patient characteristics. Asterisks indicate statistical difference between compared groups ( $p<0.05, \chi^{2}$ test). Head and neck group was excluded from comparison due to low number of employed patients

\begin{tabular}{|c|c|c|c|c|c|c|c|c|c|c|c|c|c|c|}
\hline & & \multicolumn{4}{|c|}{ Radiated body region } & \multicolumn{3}{|c|}{$\mathrm{BMI}$} & \multicolumn{3}{|c|}{ Cigarettes } & \multicolumn{3}{|c|}{ Alcohol } \\
\hline & & $\begin{array}{l}\text { Head } \\
\text { and } \\
\text { neck }\end{array}$ & Breast & Prostate & $p$ & Normal & Overweight & $p$ & $\begin{array}{c}\text { Non- } \\
\text { smoking }\end{array}$ & Smoking & $p$ & $\begin{array}{c}\text { Non- } \\
\text { drinking }\end{array}$ & Drinking & $p$ \\
\hline \multirow[t]{3}{*}{ D } & $\begin{array}{l}\text { Skin inflam- } \\
\text { mation }\end{array}$ & 33.3 & 66.7 & 49.0 & * & 46.7 & 52.7 & & 55.0 & 30.0 & & 48.8 & 55.7 & \\
\hline & $\begin{array}{l}\text { Epidermis } \\
\text { exfoliation }\end{array}$ & 33.3 & 26.7 & 12.2 & & 26.7 & 14.5 & & 20.0 & 0.0 & & 18.6 & 14.8 & \\
\hline & Hair loss & 33.3 & 13.3 & 18.4 & & 20.0 & 18.2 & & 16.7 & 30.0 & & 23.3 & 11.1 & \\
\hline \multirow[t]{8}{*}{$\mathrm{N}$} & Headache & 0.0 & 20.0 & 24.9 & & 20.0 & 26.7 & & 20.0 & 30.0 & & 20.9 & 22.2 & \\
\hline & Dizziness & 33.3 & 13.3 & 30.6 & & 25.4 & 33.3 & & 26.7 & 30.0 & & 27.9 & 25.9 & \\
\hline & Somnolence & 33.3 & 20.0 & 36.7 & & 32.7 & 33.3 & & 36.7 & 10.0 & * & 27.9 & 40.7 & * \\
\hline & Insomnia & 0.0 & 20.0 & 34.7 & & 23.6 & 46.7 & * & 30.0 & 20.0 & & 23.3 & 37.0 & \\
\hline & $\begin{array}{l}\text { Concentra- } \\
\text { tion difficul- } \\
\text { ties }\end{array}$ & 0.0 & 13.3 & 22.4 & & 18.2 & 20.0 & & 20.0 & 10.0 & & 13.9 & 25.9 & \\
\hline & Mood swing & 33.3 & 33.3 & 36.7 & & 26.7 & 38.2 & & 35.0 & 40.0 & & 34.8 & 37.0 & \\
\hline & Exasperation & 33.3 & 26.7 & 34.7 & & 32.7 & 33.3 & & 33.3 & 30.0 & & 27.9 & 40.7 & \\
\hline & Depression & 66.7 & 26.7 & 34.7 & & 36.4 & 33.3 & & 35.0 & 40.0 & & 39.5 & 29.6 & \\
\hline \multirow[t]{2}{*}{$\mathrm{O}$} & $\begin{array}{l}\text { Keratocon- } \\
\text { junctivitis }\end{array}$ & 16.7 & 0.0 & 4.1 & & 6.7 & 3.6 & & 3.3 & 10.0 & & 4.6 & 3.7 & \\
\hline & Dry eye & 0.0 & 0.0 & 10.2 & & 6.7 & 7.3 & & 6.7 & 10.0 & & 4.6 & 11.1 & \\
\hline \multirow[t]{3}{*}{$P$} & Dyspnea & 0.0 & 20.0 & 28.6 & & 26.7 & 23.6 & & 25.0 & 20.0 & & 20.1 & 29.6 & \\
\hline & Pneumonia & 0.0 & 6.7 & 4.1 & & 6.7 & 3.6 & & 5.0 & 0.0 & & 4.6 & 3.7 & \\
\hline & $\begin{array}{l}\text { Impaired } \\
\text { smell }\end{array}$ & 16.7 & 6.7 & 8.2 & & 13.3 & 7.3 & & 8.3 & 10.0 & & 11.6 & 3.7 & \\
\hline \multirow[t]{3}{*}{ U } & Pollakiuria & 0.0 & 13.3 & 59.2 & * & 41.8 & 53.3 & & 45.0 & 40.0 & & 41.9 & 48.1 & \\
\hline & $\begin{array}{l}\text { Urinary in- } \\
\text { continence }\end{array}$ & 0.0 & 0.0 & 22.4 & * & 33.3 & 10.9 & * & 16.7 & 10.0 & & 9.3 & 25.9 & * \\
\hline & Cystitis & 0.0 & 13.3 & 12.2 & & 10.9 & 13.3 & & 11.7 & 10.0 & & 3.7 & 16.3 & \\
\hline
\end{tabular}

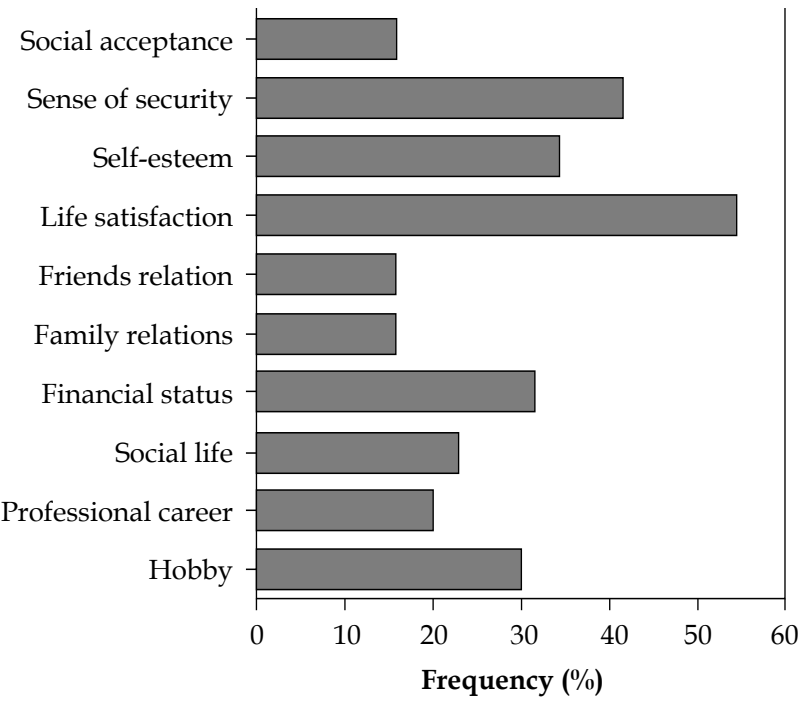

Fig. 1. The frequency of reported brachytherapy effects on the psychosocial function of treated patients and $7.1 \%$ as "intense"), for gastroenterological - weight gain $(5.7 \%$ reported it as "intense"), for neurological headaches (8.6\% reported it as "intense"), for ocular keratoconjunctivitis (1.4\% reported it as "very intense"), for pulmonological - dyspnea $(4.3 \%$ reported it as "intense"), and for urological - pollakiuria (17.1 reported it as "intense" and $7.1 \%$ as "very intense").

The number of BT treatments had a significant effect on the severity of pollakiuria $(r s=0.32, p<0.05)$, urinary incontinence ( $r \mathrm{~s}=0.31, p<0.05)$, and dyschezia ( $r \mathrm{~s}=0.29$, $p<0.05)$. Age was significantly associated with the severity of urological symptoms: pollakiuria $(r s=0.27, p<0.05)$ and urinary incontinence $(r \mathrm{~s}=0.28, p<0.05)$. Moreover, the severity of dyschezia also increased with age $(r s=0.34$, $p<0.05)$. In turn, increased BMI was followed by less severe urinary incontinence $(r s=-0.25, p<0.05)$.

As far as psychosocial side effects are concerned, patient age was negatively correlated with the severity of the effect of BT on professional careers ( $r s=-0.43, p<0.05)$. In turn, the BMI of patients was positively correlated with 
a decrease of self-esteem $(r \mathrm{~s}=0.30, p<0.05)$ and sense of security ( $r \mathrm{~s}=0.25, p<0.05)$. The number of BT treatments did not affect the severity of any of the studied psychosocial side effects.

\section{Discussion}

The study aimed to evaluate the frequency and severity of side effects induced by LDR BT or HDR BT treatment. As demonstrated, the therapy may induce various physical and psychosocial consequences, although their severity depended on several factors. In general, cigarette smokers suffered more commonly from gastroenterological effects while being overweight and consumption of alcohol increased the occurrence of various gastroenterological, neurological, and urological symptoms. The severity of the latter was also found to increase with patient age.

As anticipated, the number of treatments and the irradiated body part was also an important factor in differentiating the frequency and severity of the studied side effects. Despite the fact that BT allows overall exposure to radiation to be decreased and radiation does not disperse significantly through the body, it may still induce various systemic effects. The present study demonstrated that prostate BT treatment can induce a high frequency of urological effects, mainly urinary incontinence and pollakiuria, which is in line with other studies [13, 14]. These symptoms arise due to the close proximity of the bladder and are not usually long-term [15]. It was however observed that for some patients dysuria may last up to as long as 1 year after BT treatment [16]. Importantly, pollakiuria has also been reported by patients with irradiated breast cancer indicating that the side effects of BT may not necessarily be site-specific.

As presented above, treatment of the head/neck area with BT resulted in an increased frequency of dysphagia and chewing difficulties compared to other body parts. Nevertheless, in comparison with conventional radiotherapy and chemoradiotherapy, BT substantially reduces the dose delivered to neighboring tissues, specifically the neighboring swallowing structures $[17,18]$. In the present study, dysphagia was reported by over $30 \%$ of patients undergoing treatment of the head and neck area. However, these patients demonstrated the lowest rate of gastrointestinal side-effects with several symptoms not reported to occur at all. Importantly, this group of effects, common among patients treated in the chest or prostate area, does not demonstrate late toxicities [10], and most of them can be treated using conventional and widely available methods (e.g. diarrhea). It should be, however, noted that size of the group treated at head and neck area was low and that further studies, employing larger number of patients are necessary to fully assess the short-term toxicities in this particular treatment.

The most important finding of the present study is the role of age, BMI, cigarette smoking, and alcohol consumption in the occurrence and severity of BT side effects. As demonstrated, being overweight increased the occurrence of dyschezia and insomnia, having a distinct impact on the severity of the former. Interestingly, urinary incontinence was reported less often in this group.
This is likely to be associated with an increased content of fatty tissue in overweight individuals, and consequently higher absorption of ionizing radiation and prevention of its further dispersion $[19,20]$.

Brachytherapy has previously been shown to profoundly affect the patients quality of life $[8,21]$. In the present study, a decrease in life satisfaction, sense of security, and self-esteem were among the most frequently reported psychosocial effects. The two former effects were, however, more common in the group of overweight subjects. Various cross-sectional studies have shown that people who are overweight or obese demonstrate lower health-related quality of life [22, 23, 24]. Therefore, their baseline psychosocial characteristics may be decreased compared to patients of normal weight, and therefore the effect of BT on their lives may be more significant.

In conclusion, BT treatment is associated with differences in the frequency of a variety of physical and psychosocial side effects. The present study shows that it is possible to identify groups of patients who may be characterized by an increased susceptibility to some of these effects. For example, patients treated for prostate cancer can be expected to suffer more often from gastroenterological symptoms, while cigarette smoking can be associated with a higher frequency of dyschezia, nausea, and weight loss. Overweight patients may be more susceptible to such effects as insomnia and dyschezia, as well as being more likely to experience a decrease in selfesteem and sense of security following BT treatment. These findings are important if one considers that some of the studied factors shown to increase the occurrence and severity of particular BT side effects are modifiable prior to therapy or can be prevented. In other cases, patients should be advised of the possible increased risk of particular adverse events resulting from the treatment, so as to forewarn them and ensure that they are able to prepare themselves mentally for the upcoming therapy.

\section{Disclosure}

Authors report no conflict of interest.

\section{References}

1. Lukens JN, Gamez M, Hu K et al. Modern brachytherapy. Semin Oncol 2014; 41: 831-847.

2. Kovács G. Modern head and neck brachytherapy: from radium towards intensity modulated interventional brachytherapy. J Contemp Brachytherapy 2014; 6: 404-416.

3. Lönn S, Gilbert ES, Ron E et al. Comparison of second cancer risks from brachytherapy and external beam therapy after uterine corpus cancer. Cancer Epidemiol Biomarkers Prev 2010; 19: 464-474.

4. Morton GC, Hoskin PJ. Brachytherapy: current status and future strategies - can high dose rate replace low dose rate and external beam radiotherapy? Clin Oncol (R Coll Radiol) 2013; 25: 474-482.

5. Skowronek J. Low-dose-rate or high-dose-rate brachytherapy in treatment of prostate cancer - between options. J Contemp Brachytherapy 2013; 5: 33-41.

6. Petignat $P$, Roy M. Diagnosis and management of cervical cancer. BMJ 2007; 335: 765-768.

7. Tobias J, Monson K, Gupta N et al. Chemoradiotherapy for locally advanced head and neck cancer: 10-year follow-up of 
the UK Head and Neck (UKHAN1) trial. Lancet Oncol 2010; 11: 66-74.

8. Acar C, Schoffelmeer CC, Tillier C et al. Quality of life in patients with low-risk prostate cancer. A comparative retrospective study: brachytherapy versus robot-assisted laparoscopic prostatectomy versus active surveillance. J Endourol 2014; 28: 117-124.

9. Malcolm JB, Fabrizio MD, Barone BB et al. Quality of life after open or robotic prostatectomy, cryoablation or brachytherapy for localized prostate cancer. J Urol 2010; 183: 1822-1828.

10. Ghadjar P, Oesch SL, Rentsch CA et al. Late toxicity and five year outcomes after high-dose-rate brachytherapy as a monotherapy for localized prostate cancer. Radiat Oncol 2014; 9: 122.

11. Bandera L, La Face B, Antonioli C et al. Survival and toxicity of radical radiotherapy (with or without brachytherapy) for FIGO stage I and II cervical cancer: a mono-institutional analysis. Eur J Gynaecol Oncol 2014; 35: 121-127.

12. Grills IS, Martinez AA, Hollander M et al. High dose rate brachytherapy as prostate cancer monotherapy reduces toxicity compared to low dose rate palladium seeds. J Urol 2004; 171: 1098-1104.

13. McElveen TL, Waterman FM, Kim H et al. Factors predicting for urinary incontinence after prostate brachytherapy. Int J Radiat Oncol Biol Phys 2004; 59: 1395-1404.

14. Usmani N, Leong N, Martell K et al. Single-nucleotide polymorphisms studied for associations with urinary toxicity from (125)I prostate brachytherapy implants. Brachytherapy 2014; 13: 285-291.

15. Frank SJ, Pisters LL, Davis J et al. An assessment of quality of life following radical prostatectomy, high dose external beam radiation therapy and brachytherapy iodine implantation as monotherapies for localized prostate cancer. J Urol 2007; 177: 2151-2156.

16. Brumm J. Brachytherapy as a treatment option for prostate cancer: overview and nursing considerations. Proc (Bayl Univ Med Cent) 2000; 13: 227-229.

17. Eisbruch A, Levendag PC, Feng FY et al. Can IMRT or brachytherapy reduce dysphagia associated with chemoradiotherapy of head and neck cancer? The Michigan and Rotterdam experiences. Int J Radiat Oncol Biol Phys 2007; 69 (2 Suppl): S40-S42.

18. Eisbruch A, Schwartz M, Rasch C et al. Dysphagia and aspiration after chemoradiotherapy for head-and-neck cancer: which anatomic structures are affected and can they be spared by IMRT? Int J Radiat Oncol Biol Phys 2004; 60: 14251439.

19. Kase KR. The dosimetry of ionizing radiation. Academic Press, Inc, New York 1990.

20. Lim J, Durbin-Johnson B, Valicenti R et al. The impact of body mass index on rectal dose in locally advanced cervical cancer treated with high-dose-rate brachytherapy. Brachytherapy 2013; 12: 550-554.

21. Brandeis JM, Litwin MS, Burnison CM et al. Quality of life outcomes after brachytherapy for early stage prostate cancer. J Urol 2000; 163: 851-857.

22. Jia H, Lubetkin EI. The impact of obesity on health-related quality-of-life in the general adult US population. J Public Health (Oxf) 2005; 27: 156-164.

23. Kortt MA, Dollery B. Association between body mass index and health-related quality of life among an Australian sample. Clin Ther 2011; 33: 1466-1474.

24. Kearns B, Ara R, Young T et al. Association between body mass index and health-related quality of life, and the impact of self-reported long-term conditions - cross-sectional study from the south Yorkshire cohort dataset. BMC Public Health 2013; 13: 1009. 